\title{
MEMORIAL SOBRE A TRAJETÓRIA ESCOLAR BÁSICA DE MAURICIRLENE DA SILVA DOS SANTOS
}

\author{
Mauricirlene da Silva dos Santos ${ }^{1}$
}

Resumo: O presente texto trata do memorial sobre a trajetória escolar de Mauricirlene da Silva dos Santos, ex-integrante do Programa Conexões de Saberes. Tem como objetivo apresentar os passos percorridos desde o início da educação básica até a entrada à UFPA e quais os principais entraves de estudantes das comunidades populares adentrarem o ensino superior público. A memória foi usada como principal referência para construção do material. Em seus resultados, apresenta os esforços individual e coletivo para que de fato a educação seja uma questão de direito e não de privilégio de poucos.

Nasci entre tantas outras crianças que vieram ao mundo no dia 03 de março de 1986. Surgi num contexto social que é a cara do nosso Brasil. Sou oriunda de pais semi-analfabetos, não assalariados, que praticavam a agricultura como meio de sobrevivência. Naturalmente maranhense, nasci no município de Urbano Santos; filha de Antônio José Leocádio dos Santos (já falecido) e Maria Roza da Silva dos Santos; minha família é formada por mais 07 irmãos.

Tive uma infância semelhante à das demais crianças pobres das demais regiões brasileiras. Meus pais me colocaram cedo para trabalhar na roça. O trabalho infantil no Brasil, ainda é um problema sério a se resolver. E como alguém que questiona essa triste realidade, posso dizer que fiz parte desse contexto, no qual não me orgulho devido aos motivos de caráter desigual que atormentam muitas famílias. (por exemplo, uma má distribuição de renda que contribui com as desigualdades sociais).

Fiz parte de uma realidade em que desde cedo tive que enfrentar certas situações, que não são apropriadas para infância de alguém. O que caracterizou a minha infância não foi só as brincadeiras, mas a responsabilidade de desenvolver alguma atividade, como por exemplo, o trabalho na agricultura (capinar, plantar, colher e outros), além disso, era comum sair às ruas para vender o que se produzia (maxixe, quiabo, farinha, milho, feijão, etc.). De alguma forma eu estava contribuindo para o sustento da minha família. Por outro lado me dedicava aos estudos sob o apoio de meus pais. Considerava-me também, sonhadora, pois gostava de fantasiar que um dia iria poder brincar com a boneca dos meus sonhos e que iria para a escola

\footnotetext{
${ }^{1}$ Graduada em Licenciatura Plena em Letras pela Universidade Federal do Pará e em Letras pela Universidade de Uberaba, e-mail: conexoesmulticampi@yahoogrupos.com.br
}

Revista PET Interdisciplinar e Programa Conexões /UFPA On-line. Ed. Especial - 2017, BELÉM/ PA - ISSN 2447-097X 
com uniforme, igual aos meus colegas de aula. Hoje, olho em volta e assisto novamente a esse filme encenado por outras personagens, (crianças pobres em todo o Brasil).

Aos cinco anos de idade comecei a freqüentar a escola. No meu processo educacional, a figura de meu pai surge como um dos principais responsáveis. Antônio José, um pequeno agricultor, filho de analfabeto, sabia apenas escrever seu nome e lia muito pouco, preocupado com a educação de suas filhas fundou no bairro do Bandeira uma escola, pois até então não tinha nenhuma instituição de ensino naquele local. E em seguida procurou as entidades governamentais do município de Urbano Santos para legalizar a escola.

A partir de então, eu, minhas irmãs e as outras crianças do bairro passaram a estudar no conhecido Barracão. Era uma escola que não foge muito das características apresentada pela maioria das escolas no interior maranhense. Paredes de barro, coberta de palha, o quadro negro e no centro uma mesa grande rodeada de bancos. A escola localizava-se em uma rua de piçarra afastada do centro da cidade.

Faço questão de enfatizar isso, para estabelecer uma relação entre a escola em que estudei há 17 anos, com as demais escolas que ainda hoje se encontram no mesmo estado crítico. Um programa de televisão mostrou uma reportagem sobre as várias escolas municipais em vários estados, que estavam praticamente abandonadas pelas entidades governamentais. Escolas sem estrutura de funcionamento, no qual os professores precisavam improvisar as salas de aulas. No Maranhão a professora dava aula até debaixo de uma mangueira.

Diante disso, existem perguntas que não querem calar. Para onde estão sendo destinadas as verbas que dizem serem liberadas para a educação?

Voltando a minha história, posso dizer que com o passar do tempo fui crescendo mudando de escola de acordo com o nível de escolaridade. Estudei na escola Andrelina dos Santos Carvalhos da $2^{\mathrm{a}}$ a $4^{\mathrm{a}}$ série. No ano de 1998 fui cursar a $5^{\mathrm{a}}$ série até o $1^{\mathrm{o}}$ ano do ensino médio na escola Chagas Araújo. Nesse período, se a vida era difícil, tornou-se ainda mais, devido à doença de meu pai que durou 10 anos até o seu falecimento em 07 de outubro de 2006.

Fiz parte da primeira turma que fez o ensino médio na cidade de Urbano Santos. Até então o que se tinha, era o magistério. No ano de 2002, foram inovadas as diretrizes do sistema educacional beneficiando a escola Chagas Araújo com a implantação do Ensino Médio. Um grande avanço se percebeu em relação ao sistema educacional, mas em relação aos fatores responsáveis pela concretização desse plano, enfrentaram-se vários problemas. 
Fomos de certa forma, prejudicados devido à falta de professores formados em determinadas áreas. Por exemplo, professor formado em matemática dava aulas de química, professor formado em português tinha que cobrir a carência de professores das matérias de inglês, sociologia e outras. São essas lacunas que se percebe na educação e que de alguma forma contribui para que o nosso país não esteja entre os melhores em nível educacional. Os investimentos liberados pelo governo ainda são fragmentados e frequentemente são desviados do seu destino.

Dentro do contexto no qual estava não foi fácil cursar o $1^{\circ}$ ano do ensino médio, devido os contratempos que ocorreram. Como eu já venho citando desde o início, são os problemas financeiros e a doença de meu pai que insistiam em me acompanhar e toda a minha família. Porém, posso também falar de situações interessantes que fazem parte da minha vida estudantil. Tive a oportunidade de elevar meu conhecimento com relação ao leque de informações dadas por parte dos meus professores, mantive uma boa relação com os colegas de aula, professores direção da escola, no qual me orgulho muito, de ter aproveitado o que me propuseram.

Desde criança meu sonho era chegar a uma universidade e me formar em história, como o município onde morava, só tinha até o ensino médio, resolvi sair de minha cidade e buscar a materialização do mesmo. Devido presenciar o sofrimento de minha família, meu pai doente sem ter condições de trabalhar, minha mãe sozinha tinha que cumprir o papel de mãe e pai; não tinha condição de dar as suas filhas uma situação de vida melhor; tudo isso, me motivou a desprender-me do aconchego familiar e migrar para uma cidade que proporcionasse outra opção de vida.

Como tenho uma irmã que mora em Capanema (Pará) resolvi vim morar com ela, pois acreditava que tudo seria mais fácil. Então no dia 21 de janeiro de 2003 cheguei à cidade do cimento. Matriculei-me na escola Oliveira Brito, na qual cursei o $2^{\circ}$ e $3^{\circ}$ ano do ensino médio. A princípio percebi uma grande diferença na metodologia de ensino; houve alguns momentos em que fui criticada pela minha forma de falar. Na verdade sofri por não ser paraense e por não ter muito conhecimento sócio-cultural da região e principalmente por estar longe da minha família.

Terminei meu ensino médio, mas pretendia elevar meu grau de escolarização, ou seja, fazer cursos preparatórios para o vestibular. Então decidi trabalhar em casa de família para poder pagar o cursinho. Ouso dizer que foi muito proveitoso, tive novamente contato com o

Revista PET Interdisciplinar e Programa Conexões /UFPA On-line. Ed. Especial - 2017, BELÉM/ PA - ISSN 2447-097X 
conhecimento nas suas várias formas pedagógicas. Nesse percurso fiz várias amizades, ou seja, encontrei pessoas que me deram muito apoio.

Em 2005, apesar de estudar o ano todo não me inscrevi para o vestibular, pois, no período de inscrição não tinha dinheiro e não fui contemplada com a isenção. Mas no ano de 2006, estava novamente matriculada no cursinho, mais segura para a disputa de uma vaga na universidade.

De fato, foi o que aconteceu, depois de vários meses de estudo, inscrevi-me na UEPA e na UFPA, realizei todas as provas da estadual e federal, mas, somente na federal consegui ser aprovada no curso de letras para a cidade de Bragança, Nordeste do Pará.

Mais uma vez me coloco como exemplo das dificuldades enfrentadas por diversos estudantes de origem popular. No entanto, dessa vez, estou em uma instituição de ensino superior tentando dar um passo a frente nessa longa estrada. Nos primeiros meses de curso lidei com a falta de moradia, pois não tinha um local certo para ficar e não tinha condições para pagar aluguel, até o material (apostilhas), às vezes não comprava. A solução que encontrava, era conseguir um emprego, mas, as empresas alegam que o mercado de trabalho é bastante escasso para as pessoas que tem disponível apenas um horário para trabalhar (que é o meu caso).

A universidade para mim está sendo um grande desafio, uma experiência na qual, tenho que passar por várias provas de resistência, para poder manter o meu curso em Bragança; principalmente a situação se agrava ainda mais, quando pouco se pode contar com o apoio financeiro da família. Diante disso, se pode ter uma base do que um universitário de origem popular passa para conseguir atingir seus objetivos; isto é, concluir a graduação.

Eis que uma nova oportunidade surgiu-me. No mês de maio, de 2007 a coordenação de extensão de Bragança estava disponibilizando 05 bolsas para estudante de origem popular. Como me enquadro nesse perfil, realizei minha inscrição e consegui uma bolsa de ensino e pesquisa do Programa Conexões de Saberes.

A partir do momento que começaram os trabalhos, fui me identificando e percebendo o quanto o programa poderia me ajudar no sentido de trazer informações que poderia acrescentar ao meu curso e também serviria para preencher cargas horárias, como atividades extracurriculares. É claro que a bolsa em si, é uma forma de garantir minha permanência com qualidade na universidade.

Conexões é um programa que está voltado para as ações afirmativas que procura discutir políticas de acesso e permanência dos estudantes de origem popular nas 
Universidades Federais. Considero-me, causa pelo qual o programa luta, e ao mesmo tempo, sou privilegiada por contribuir para que o conexões desse seu primeiro passos em Bragança. As atividades realizadas pela equipe do programa, foram voltadas para a discussão e elaboração de propostas que viessem beneficiar os estudantes de origem popular; uma forma de atenuar para os problemas que os estudantes passam e normalmente a coordenação, professores da instituição, não tem conhecimento de tais fatos.

De certa forma, o programa veio abraçar, uma causa séria, dar uma nova versão para a história da universidade, destacando como protagonista, do enredo aqueles que se sentiam inferiores aos outros, desprezados, aqueles que sofriam o preconceito racial, social, que vieram de famílias pobres, porém, que se incluem em uma instituição de Ensino Superior. E para facilitar a permanência desses personagens, o programa Conexões veio contribuir tanto no aspecto cultural, informacional, social e financeiro; com isso, demonstra que a universidade não é só para aqueles que têm condição financeira, mas para todos. Posso dizer que aceitei um desafio na vida e hoje, sou universitária e o programa conexões tem contribuído parcialmente para minha permanência nessa Instituição Federal de Ensino Superior. 